\title{
SUBSERVIÊNCIA AO CAPITAL: EDUCAÇÃO AMBIENTAL SOB O SIGNO DO ANTIECOLOGISMO
}

\author{
Philippe Pomier Layrargues ${ }^{1}$
}

\begin{abstract}
Resumo
A presente reflexão, partindo dos pressupostos da Ecologia Política e ancorada na perspectiva teórica de Althusser, Bourdieu e Passeron, Gramsci e Freire, contextualiza o atual quadro conjuntural histórico-crítico da luta ambiental, caracterizada como estando sob o signo do Antiecologismo por estar impregnada pelo receituário neoliberal, que enseja a desregulamentação ambiental pública para promover o ambiente de negócios ideal ao setor extrativo primário da economia; para analisar como, quando e porque o campo da Educação Ambiental brasileira se converteu em um aparelho ideológico de Estado a serviço de um modelo reprodutivista de educação, pautado pela pedagogia do consenso da ideologia do ambientalismo de mercado como estratégia da manutenção da hegemonia burguesa subserviente ao capital. Analisa, também, os desafios políticos para a recuperação do seu inerente poder subversivo e contestatório, que lhe foi subtraído, condição necessária à superação da cooptaçãoideológica da sociabilidade neoliberal, para pavimentar a hegemonização da Educação Ambiental Crítica, pensada e praticada a partir da perspectiva anticapitalista e do oprimido; comprometida,simultaneamente, com a denúncia da insustentabilidadedo desenvolvimentismo e com o anúncio das Sociedades Sustentáveis.
\end{abstract}

Palavras-chave: Educação Ambiental. Antiecologismo. Aparelho Ideológico de Estado. Educação Reprodutivista.

\section{SUBSERVICE TO CAPITAL: ENVIRONMENTAL EDUCATION UNDER THE SIGN OF ANTI-ENVIRONMENTALISM}

\begin{abstract}
The present reflection, based on the assumptions of Ecopolitics and anchored in the theoretical perspective of Althusser, Bourdieu and Passeron, Gramsci and Freire, contextualizes the current historical-critical conjuncture of the environmental struggle, characterized as being under the sign of Anti-Environmentalism, impregnated by the neoliberal recipe that leads to public environmental deregulation to promote the ideal business environment to the primary extractive sector of the economy; to analyze how, when and why the field of Brazilian Environmental Education has become an ideological state apparatus in the service of a reproductive model of education, based on the pedagogy of the consensus of the ideology of market environmentalism as a strategy for the maintenance of bourgeois hegemony subservient to capital.It also analyzes the political challenges for the recovery of its inherent subversive and contestatory power that has been subtracted from it, a necessary condition for overcoming the ideological cooptation of neoliberal sociability, to pave the hegemonization of Critical Environmental Education, thought and practiced from the anticapitalist and oppressed; committed simultaneously with denouncing the unsustainability of developmentalism and with the announcement of Sustainable Societies.
\end{abstract}

Keywords: Environmental Education.Anti-Environmentalism.Ideological State Apparatus.Reproductive Education.

${ }^{1}$ Professor Doutor do Curso de Gestão Ambiental da Universidade de Brasília. philippe.layrargues@ gmail.com 


\title{
SUBSERVIENCIA AL CAPITAL: EDUCACIÓN AMBIENTAL BAJO EL SIGNO DEL ANTI-ECOLOGISMO
}

\begin{abstract}
Resumen
La presente reflexión, partiendo de los presupuestos de la Ecología Política y anclada en la perspectiva teórica de Althusser, Bourdieu y Passeron,Gramsci y Freire, contextualiza el actual cuadro coyuntural histórico-crítico de la lucha ambiental, caracterizada como estando bajo el signo del Anti-ecologismo por estar impregnada por el recetario neoliberal que plantea la desregulación ambiental pública para promover el ambiente de negocios ideal al sector extractivo primario de la economía; para analizar cómo, cuándo y por qué el campo de la Educación Ambiental brasileña se convirtió en un aparato ideológico de Estado al servicio de un modelo reproductivista de educación, pautado por la pedagogía del consenso de la ideología del ambientalismo de mercado como estrategia del mantenimiento de la hegemonía burguesa subserviente al capital. También, analiza los desafíos políticos para la recuperación de su inherente poder subversivo y contestatario que le fue sustraído, condición necesaria para la superación de la cooptación ideológica de la sociabilidad neoliberal, para pavimentar la hegemonización de la Educación Ambiental Crítica, pensada y practicada desde la perspectiva anticapitalista y de los oprimidos; comprometida, simultáneamente, con la denuncia de la insostenibilidad del desenvolvimiento y con el anuncio de las Sociedades Sostenibles.
\end{abstract}

Palabras clave: Educación Ambiental. Anti-Ambientalismo. Aparato Ideológico de Estado. Educación Reproductivista.

\section{A luta ambiental sob o signo do Antiecologismo}

Ao mesmo tempo em que se vivencia uma profunda crise política, institucional e econômica no Brasil, o país consolidao papel geopolítico global periférico como uma naçãoprovedora de commodities, como eixo estruturante do projeto desenvolvimentista brasileiro. Calcado na modernização pública da infraestrutura e no fortalecimento da iniciativa privada no setor primário da economia, promove o extrativismo predatório, aquele que elimina os entraves à lógica da redução dos custos de produção das commodities, aí incluída a supressão dos direitos ambientais e humanos, quando advoga por mais racionalidade de mercado com a privatização e mercantilização da natureza e menos interferência do Estado na regulação ambiental.

A comunidade ambiental brasileira reconhece estar diante de um inimaginável processo de severa desregulação da política e da gestão ambiental pública, não apenas no Brasil, mas em todo continente. Assiste-se, perplexa e cotidianamente, tão surpreendentes quão lamentáveis reportagens, relatórios e manifestos denunciando recorrentes casos de retrocessos ambientais como a alteração da legislação ambientale o sucateamento de órgãos ambientais, algo que indica um expressivo e complexo recuo das institucionalidades públicasde defesa ambiental.

Observando o quadro a partir da perspectiva da Ecologia Política e do Pensamento Ambiental Latino-americano, nota-se haver uma determinação comum que envolve um amplo, diversificado, coeso e articulado conjunto de práticas que demarcam, não apenas a degradação ambiental e os conflitos socioambientais (associação já identificada desde o início dos anos 80, com o surgimento do movimento contra o racismo ambiental nos EUA), mas que envolvem, também, o desmonte e aparelhamento político da gestão ambiental governamental, o afrouxamento dos marcos regulatórios da legislação ambiental disciplinadora do acesso aos recursos naturais, a retórica desqualificadora dos ethos ecologistas de matriz preservacionista 
e crítico, as ameaças jurídicas e de integridade física até o assassinato de lideranças ambientais e do campo, a perda dos direitos territoriais dos povos das florestas.

Esse complexo conjunto de práticas comprometedoras da construção da sustentabilidade orientada pela defesa do interesse público e do bem comum, se encontra amplamente disseminado em todos os âmbitos da vida, no pensamento social, no poder executivo, legislativo e judiciário, e seu efeito sistêmico converge para o quadro da aguda intensificação da desregulação ambiental pública em que vive o país desde meados da primeira década do século 21.

Analisando o conjunto desses fragmentos do esfacelamento das institucionalidades ambientais públicas a partir do enquadramento teórico dos aparelhos ideológicos de estado de Althusser (1970); dos mecanismos ideológicos de reprodução social de Bourdieu e Passeron (1992), e da noção de Hegemonia de Gramsci, é possível compreender o quadro geral e perceber que, na raiz dessas situações aparentemente desconexas, percebidas como fenômenos distintos e sem relações entre si, de tão particulares que seriam, está o signo do Antiecologismo ${ }^{2}$.

Com o antiecologismo, desponta um novo período, inédito, o momento em que surgem vozes dissonantes no horizonte da sustentabilidade, apontando para seus limites, e a configuração das forças em disputa é significativamentealterada, em desfavor da proteção ambiental.

Enquanto uma questão ideológica, a questão ambiental gira em torno da luta política pelo poder de significação de projetos societários em disputa; nesse sentido, a construção da sustentabilidade é demarcada pela luta ambiental, antagonizando a racionalidade econômica e seu desenvolvimentismo economicista, e a racionalidade ecológica, com seu respectivo pleito pelo direito por outros modos de existência autônomas, para além do desenvolvimentismo capitalista.

Trata-se de uma correlação de forças em disputa, antagonizando diferentes posturas, na oposição entre economia x ecologia; mas com outras clivagens equivalentes, como a oposição entre a canonização da soberania suprema da propriedade privada $\mathrm{x}$ a ressignificação da função social da propriedade privada (agora, calcada no provimento gratuito dos serviços ecossistêmicos). Essa mesma clivagem é atravessada pelo conflito de classe, antagonizando o capital e o trabalho e um ambientalismo de mercado e um ecologismo popularcomo fundamentos dos projetos societários em disputa.

Como correlação de forças, há alternância nesse antagonismo que se sucede ao longo do tempo, em função das conjunturas históricas de cada época e da renovação das estratégias do exercício do poder, que implicam em avançosou retrocessos. Recuos e avanços fazem parte de toda luta política, como essa verdadeira luta ambiental que se processa cotidianamente no destino da regulação ambiental pública, dependendo da correlação do poder das forças desenvolvimentistas e sustentabilistas em cada conjuntura histórica, contrapondo-se à liberalização da economia e à mercantilização da natureza contra a regulação ambiental pública,definidora dos limites da atividade econômica, para que seu inerente impacto ambiental não ponha em risco a base natural de sustentação da vida e acarrete no colapso ambiental.

Dessa perspectiva, na trajetória da luta ambiental desde os anos 60, a partir do surgimento do signo do Antiecologismo, teve início a quarta fase do antagonismo entre a ecologia e a economia:

Na primeira fase da luta ambiental, ainda nas raízes do ecologismo, havia, nos anos 1960, um predomínio absoluto da ideia desenvolvimentista calcada no crescimento

\footnotetext{
${ }^{2}$ Para uma abordagem mais detalhada sobre o Antiecologismo, ver Layrargues (no prelo).
} 
econômico, relegando o nascente debate ambiental com a defesa ecológica ao segundo plano, a um debate de menor importância. Foi nesse ambiente inóspito que germinou a base discursiva que vigorou por toda a era de ouro do ecologismo, as últimas quatro décadas: a noção de limites naturais e de finitude dos recursos naturais não renováveis, advinda em função das primeiras imagens da Terra a partir do espaço, captadas em 1966, pelo satélite Lunar Orbiter 1.

A existência de limites dados pela natureza do cosmo, equivalendo o planeta Terra a um pálido ponto azul no espaço, como definiu Carl Sagan, inspirou o surgimento da metáfora da nave espacial Terra, que, por sua vez, deu todo o amparo argumentativo para os Profetas do Apocalipse criarem a narrativa da crise ecológica como uma crise planetária, catastrófica e irreversível, qualificando como inadiável e urgente a tarefa de combater a insustentabilidade.

Signo de catástrofe acrescido, pouco mais de uma década depois, pela narrativa da fragilidade do planeta Terra diante da ação antrópica, proporcionada pela publicação de Gaia, de Lovelock (1979). E essa inadiável tarefa de combater a crise ecológica se realizaria, a contragosto, pela aplicação do princípio da precaução impondo limites à economia. Agora, com um Estado regulador em nome da proteção ambiental, a plena liberalização da economia e mercantilização da natureza ficaria entravada por quase três décadas. A ideia do apocalipse global que se abateria sobre o planeta, caso não se adotasse outro rumo ${ }^{3}$, prevaleceu, justificada como um debate de grande relevo.

Foi sustentado por esse argumento da poderosa ideia de uma crise ambiental catastrófica que emergiu a segunda fase daluta ambiental, onde se verifica, a partir de 1972, com a notável influência do Clube de Roma e seu relatório Limites do Crescimento (MEADOWS, 1972), depois sustentado pela Conferência de Estocolmo, o fim daprimeira fase,com uma inversão completado primado da economia, sendo substituído pelo primado da ecologia, dando lugar ao início da era ambiental. É nesse contexto que se fundou todas as institucionalidades ambientais públicas que passaram a sustentar os instrumentos de proteção ambiental.

Essa segunda fase perdurou até 1992, quando, no marco na Conferência do Rio, mas amparado antes pelo Relatório da Comissão Mundial de Meio Ambiente e Desenvolvimento, publicado em 1987, ocorreu um sutil movimento nessa correlação de forças, que tendia à hegemonia da ecologia sobre a economia, para entrar numa nova equação, agora apaziguada e idealizada como harmoniosa, a partir da formulação discursiva do Desenvolvimento Sustentável. A tensão desapareceria com a sinalização do equilíbrioe,finalmente, estaria estabelecido o pacto histórico do fim desse antagonismo na luta ambiental, em nome das gerações futuras.

O fiel da balança que sustentou o argumento do equilíbrio entre desenvolvimento e sustentabilidade se baseou na recém-fundada narrativa do ambientalismo empresarial, protagonizado pelo setor secundário da economia, de que o investimento na qualidade ambiental representava, agora, uma oportunidade competitiva de negócios, já que o mercado principiava a sinalizar a existência de mecanismos capazes de internalizar os custos ambientais, a exemplo do Consumidor Verde (LAYRARGUES, 1998, 2000). A economia teria encontrado seus mecanismos próprios de imposição de restrições ambientais à atividade produtiva.

Ocorre que é justamente nessa terceira fase que se verifica a primeira influência neoliberal sobre a regulação ambiental pública, em que os instrumentos de comando e controle foram substituídos pelos mecanismos de mercado para regular a poluição industrial.

\footnotetext{
${ }^{3}$ Não é por acaso que a obra que determinou a conversão do capital ao imperativo ecológico, demarcando o nascimento do ambientalismo empresarial, foi intitulada "Mudando o Rumo" (SCHMIDHEINY, 1992), e que principia a difundir a lógica do ambientalismo de mercado.
} 
Mas, mesmo com essa singularidade da perda de hegemonia da ecologia com o recuo do papel do Estado na regulação do interesse público, a segunda e terceira fase desse antagonismo representaram a época de ouro para o ecologismo, o período da bonança ambiental, onde se consolidaram os fundamentos da proteção ambiental como um bem público e direito difuso assentado sob o princípio da precaução.

Essa época de ouro do ecologismo no Brasil encontra seu fim a partir de 2006, quando, em cerimônia de inauguração de uma usina de biodiesel, o então presidente Lula qualificou o Licenciamento Ambiental como um entrave ao desenvolvimento, se referindo à morosidade e rigor desse procedimento de gestão com relação às obras de infraestrutura do Programa de Aceleração do Crescimento. Essa afirmação foi o estopim que iniciou a surpreendente e abrupta reconfiguração da luta ambiental, que ganhou um inesperado contorno nessa correlação de forças sociopolíticas: o PAC se constituiu como o divisor de águas dessa quarta fase da luta ambiental, onde a economia abandona o pacto da sustentabilidade e retoma a antiga hegemonia sobre a ecologia.

Foi o primeiro ato do drama social como um evento culminante que alterou completamente o cenário sustentabilista, com a eclosão de um conflito explícito na relação entre o ecologismo e o desenvolvimentismo economicista, quebrando a aliança do desenvolvimento sustentável. Não é pequena a influência que um presidente da república exerce, especialmente quando se verifica que, se dependesse de sua vontade, ele desarticularia toda institucionalidade ambiental que, supostamente, freava o progresso do país, como diagnosticou Gudynas (2009). Decretava-se, com a fala do ex-presidente Lula, a ameaça de que a proteção ambiental não deveria mais entravar a economia, seus dias de glória estariam contados.

O segundo ato se constituiu no contexto do auge da crise econômica e política, no governo de Dilma Roussef. Haja vista as centenas de projetos de lei que passaram a tramitar nas assembleias legislativas de todo país, direcionados a alterar os marcos regulatórios da legislação ambiental e das Unidades de Conservação; as recorrentes denúncias de sucateamento dos órgãos ambientais, prosseguindo com o desmantelamento neoliberal da estrutura administrativa da gestão ambiental pública, numa voracidade jamais vista antes no setor governamental.

A narrativa da melhoria do ambiente de negócios como superação da crise econômica serviu como justificativa da doutrina neoliberal, a pretexto de o Estado invocar o interesse nacional da imperativa retomada do crescimento que se daria em detrimento das institucionalidades ambientais públicas, que estariam entravando o projeto desenvolvimentista brasileiro. A mensagem preceitua que a fórmula para superar a crise econômica envolve mais racionalidade de mercado e menos regulação ambiental pública. Com a eliminação dos entraves ambientais e com a expropriação dos povos tradicionais de seus direitos territoriais, elementos impeditivos do avanço do complexo modernização da infraestruturareprimarização da economia,impôs-se um sacrifício como condição de superação da crise econômica.

O terceiro ato do drama social desponta no governo Temer, em 2016, quando o conservadorismo neoliberal se instala no governo federal, acenando para a melhoria no ambiente de negócios por meio da desregulação ambiental pública. E, no âmbito das denúncias de corrupção do presidente Temer, a agenda ambiental foiconvertidanuma estratégica peça de barganha política em troca de votos parlamentares, a moeda de troca perfeita para a bancada predominante no parlamento, a ruralista, com $41 \%$ dos deputados.

E, assim, projetos de lei e projetos de decretos legislativos de interesse do agronegócio, como a redução da Floresta Nacional de Jamanxim, a tentativa de adoção do marco temporal de 1988 para a demarcação de terras indígenas e quilombolas, a dispensa de licenciamento para construção de hidrovias nos rios Tapajós, Tocantins e Araguaia, a quase 
extinção da Reserva Nacional do Cobre e seus associados, por exemplo, vieram pavimentar a legitimidade política do governo federal com a cumplicidade parlamentar.

O novo período, demarcando o signo do Antiecologismo, representa o retorno da prevalência econômica, em nome de um ajuste para reequilibrar a relação entre economia e ecologia, posto que a narrativa de sustentação do antiecologismo se baseia nos excessos cometidos na era ambiental pelo ecologismo ter sido excessivamente rigoroso com a criação de todo um aparato político-institucional de proteção ambiental, que não mais deveria inviabilizar o crescimento econômico.

$\mathrm{O}$ atual quadro do Antiecologismo evidencia o movimento em curso da abrupta alternância do poderna luta ambiental: é o retrato instantâneo de uma mudança do tempo histórico, com a reacomodação dos limites entre a ecologia e a economia. Os tempos, agora, são outros, o ciclo da bonança da era ambiental acabou.

O Antiecologismo é o resultado que prevaleceu dessa tensão que antagoniza a decisão por maximizar a proteção ambiental das florestas e dos serviços ecossistêmicos, ou maximizar a rentabilidade do extrativismopredatório dos recursos naturais, sobretudo quando contextos de crise econômica sistêmica global impõem o aprofundamento da redução dos custos de produção.

O que resulta como legado histórico desse processo é a disseminação da mensagem ideológica de que o ecologismo qualificado como radical e romântico foi longe demais com sua crítica intransigente e seu excessivo zelo preservacionista, por ter criado nas últimas décadas institucionalidades ambientais que acabaram bloqueando o crescimento econômico advindo da exploração dos recursos naturais, que ficaram impedidos de serem acessados em função desse preciosismo na proteção ambiental.

Definitivamente, aos atores do campo econômico parece ter chegado a hora de reverter essa equação que perdurou nos últimos trinta anos, para equilibrar o crescimento econômico e a sustentabilidade, na perspectiva neoliberal, já que o fiel da balança tendera demais à proteção ambiental.

Esse fenômeno fundamentalmente demarca o surgimento de um novo tempo histórico, que não se via desde os anos 1970, em que desponta uma nítida prevalência do interesse econômico a qualquer custo, em detrimento das institucionalidades ambientais públicas. Um tempo em que desponta a hegemonização da sociabilidade do capital e do ambientalismo de mercado, cuja lógica da privatização e mercantilização da natureza compromete a integridade ecológica das florestas nativas, da biodiversidade e dos serviços ecossistêmicos prestados gratuitamente pela natureza, mas, também, a existência dos povos tradicionais originais e autônomos, diante da intensificação do avanço da fronteira extrativista-predatória sobre seus territórios.

E esse também é o tempo histórico em que a Educação Ambiental foi profundamente atravessada pelo signo do Antiecologismo; quando consolidou seu conservadorismo pedagógico, tornando-se hegemonicamente reprodutivista, designada a inculcar, ideologicamente, à mais ampla audiência, a nova norma social investida ao sujeito ecológico pelo ato pedagógico da Educação Ambiental, disseminando os valores da sociabilidade do capital e omitindo o quadro histórico-crítico que contribuiria com o desnudamento das contradições da sociedade capitalista, alimentando a subversão da ordem.

Assim, no compasso das formulações narrativas ideológicas midiáticas que exercem opressão simbólica no imaginário social,ao desqualificar o pensamento ecologista em geral, mas sobretudo o ethoscrítico e preservacionista, em favor da construção de uma identidade pacificada e controlada para o ethos ecologista desejável, o moderado; também a Educação Ambiental foi modificada para contribuircom esse processo de estabelecimento de um padrão normal a ser cumprido. 
A fórmula neoliberal ampliou seus horizontes, colonizou o campo da Educação Ambiental e oressignificou em função dos seus propósitos, mantendo, assim, o processo de contínua legitimação da hegemonia. Ao tornar-se atravessada pela lógica reprodutivista, a Educação Ambiental assumiu o projeto societário capitalista: foi, enfim, quando a Educação Ambiental passou a contribuir verdadeiramente como um aparelho ideológico de Estado a serviço do capital.

\section{A hegemonização da Educação Ambiental reprodutivista no Brasil}

Já faz mais de vinte anos que o campo da Educação Ambiental brasileira sabia que sua práxis se prestava à realização de projetos societários específicos, demarcados pelos interesses da luta de classes em disputa pela hegemonia do poder:ainda no final dos anos 1980, Carvalho (1989) evidenciou haver um debate em torno de uma versão Oficial e outra Alternativa da Educação Ambiental, onde emerge o discurso liberal da responsabilização do indivíduo para o enfrentamento da crise ambiental, e de onde emergiria a perspectiva antagônica, da Educação Ambiental Crítica. Pouco depois, Loureiro (1992) demarcou o lugar a partir do qual se pensaria a Educação Ambiental brasileira, quer seja, entranhada pela perspectiva das classes populares ${ }^{4}$.

A própria carta de princípios que inspira o ideal da Educação Ambiental, o Tratado de Educação Ambiental para Sociedades Sustentáveis e Responsabilidade Global, se posiciona no campo contra-hegemônico: o princípio 4 afirma que "a educação ambiental não é neutra, mas ideológica. É um ato político, baseado em valores para a transformação social”. Ou seja, o alinhamento com a carta de princípios naturalmente coloca a Educação Ambiental no desconfortável e arriscado campo subversivo.

No início dos anos 1990, Brügger(1994) já se indagava se o que ocorria era um adestramento ambiental que tomou o lugar da Educação Ambiental, e Guimarães (2000) destacou que, já nos anos 1990, se entrevia uma Educação Ambiental ideologicamente cooptada, expandindo-se em um processo de conquista de hegemonia a partir do capital. $\mathrm{O}$ autor frisou, inclusive, que o contexto daquela época demandava redobrar os esforços em direção a uma Educação Ambiental Crítica, para assegurar a necessária compreensão conceitual acerca dos antagônicos projetos societários que permeiam a educação.

No mesmo sentido, Layrargues (2006) alertou que a Educação Ambiental brasileira estava cada vez mais desideologizada, dificultando a compreensão de que a práxis da Educação Ambiental representa um instrumento ideológico orientadopela reprodução ou transformação social, dependendo da intencionalidade político-pedagógica.

Pouco depois, Layrargues (2012) sinalizou sobre a crise de identidade que a Educação Ambiental brasileira passou a enfrentar, no início da segunda década do século 21, manifestada,primeiro, pela contradição entre teoria e prática (conforme diagnóstico de LIMA, 2011), advinda da fraqueza teórica amplamente disseminada no campo, que separa os princípios orientadores estabelecidos como corpo conceitual da Educação Ambiental Crítica, daquilo que, de fato, vinha sendo desenvolvido no âmbito das políticas e práticas educativas no contexto ambiental. E,segundo, pela dificuldade de superação do conservadorismo pedagógico no campo.O resultado foi o contínuo afastamento da crítica anticapitalista, já se

\footnotetext{
${ }^{4}$ Em 2004, Carlos Frederico B. Loureiro veio a se tornar um dosfundadores do Laboratório de Pesquisas em Educação, Ambiente e Sociedade, vinculado à Faculdade de Educação da Universidade Federal do Rio de Janeiro, que se tornou um grupo de pesquisa vanguarda no Brasil, por ter delineado o contorno teórico conceitual e metodológico da Educação Ambiental Crítica, bem como ter identificado os sintomas do processo de hegemonização do modelo reprodutivista que tomou de assalto o campo da Educação Ambiental, permitindo com isso constatar-se a vigência dos aparelhos ideológicos de Estado em ação.
} 
levantando, então, suspeitas de que a Educação Ambiental brasileira estaria se convertendo em um aparelho ideológico de Estado comprometido com o projeto reformista.

Apesar da perspectiva da Educação Ambiental Crítica se fundar exatamente a partir da problematização da insuficiência teórica e da possibilidade da cooptação ideológica,resultando em práticas conservadoras e reprodutivistasde Educação Ambiental, a preocupação predominante consistia, apenas,na fraqueza teórica presente no campo, porque não se imaginava que havia um risco de uma profunda e generalizada cooptação ideológica que chegasse não só a desfigurar a Educação Ambiental, mas tornar-se hegemônica pelo menos no âmbito da Educação Ambiental governamental e escolar, os principais aparelhos ideológicos de Estado.

De fato, o risco era alto, o campo político da Educação Ambiental brasileira conta com um arranjo político-organizacional robusto e bem estruturado, calcado numa Política e num Programa Nacional de Educação Ambiental, amparado por garantia constitucional que assegura o direito à Educação Ambiental para todo cidadão, que lhe destina, autonomamente, uma ampla e preciosa audiência sob sua influência,dada sua enorme capilaridade na escola e no tecido social brasileiro:sua presença é praticamente universal tanto na escola, como no Estado.Nessa condição, o campo da Educação Ambiental não poderia ser deixado livre para o exercício subversivo da contra-hegemonia e a crítica anticapitalista precisava ser sufocada.

Se a parceria empresa-escola protagonizada pela Latasa, em 1993, com a criação do Projeto Escola, correspondeu à infiltração inicial da lógica reprodutivista no campo da Educação Ambiental brasileira (LAYRARGUES, 2002), tendo como pano de fundo a valorização da pluralidade da Educação Ambiental atuando como um Cavalo de Tróia, permitindo a instalação de uma perspectiva pragmática na Educação Ambiental; a insuficiência teórica demarcou o solo fértil da dissimulação que fez germinar a semente infiltrada: uma prática pedagógica reducionista, instrumental, normativa, conteudista e totalmente acrítica fez passar-se de Educação Ambiental, e foi acolhida sem quaisquer objeções.

Amparado pela perspectiva dos aparelhos ideológicos de Estado, o arcabouço conceitual das macrotendências político-pedagógicas da Educação Ambiental é um quadro analítico por meio do qual é possível estabelecer, com nitidez, uma tipologia das diferentes intencionalidades presentes em cada macrotendência, cindidas pelo cunho ideológico conservador de reprodução social, ou subversivo de transformação social. O campo da Educação Ambiental, na perspectiva de suas macrotendências político-pedagógicas, encontrase demarcado sob três perfis: Conservacionista, Pragmática e Crítica (LAYRARGUES; LIMA, 2014).

Cada macrotendência possui suas características, dependendo das intencionalidades que inspiram suas práticas. Dessa forma, cada uma possui um tema-chave que lhe é central no ato pedagógico, embora não lhe seja específico: qualquer tema pode pertencer ao domínio de qualquer macrotendência. Mas, em linhas gerais, o tema-chave central que pertence idealmente à perspectiva Conservacionista gira em torno da defesa da Vida, Natureza, ecossistemas, florestas e rios, áreas protegidas e Unidades de Conservação, agroecologia, ecoturismo. Para a perspectiva Pragmática, o tema-chave que sobressai centralmente gira em torno da Gestão Ambiental privada, Ecologia Industrial, Reciclagem, inovações tecnológicas, Desenvolvimento Sustentável, Consumo e Economia Verde. Já para a perspectiva Crítica da Educação Ambiental, o tema-chave gira em torno da Ecologia Política, Educação Popular, Conflitos e Injustiça Socioambientais.

Ocorre que as macrotendências Pragmática e Conservacionista pertencem ao mesmo pacote conservador e reprodutivista, posto que o tratamento pedagógico conferido a seus temas-chave não se caracteriza como um tema-gerador (LAYRARGUES, 1999) e, então,não recebe o contorno teórico necessário para se compreender interdisciplinarmente a totalidade, 
historicidadee complexidade do fenômeno envolvente e, assim, apresentam uma visão distorcida e parcial da realidade, onde esse conservadorismo pedagógico simplesmente deixa de expor as contradições do modelo societário que está na raiz da desigualdade e da degradação socioambiental, contribuindo para que a realidade capitalista não seja problematizada.

Na compreensão de que a Educação é um ato ideológico, Siqueira e Kaplan (2014) evidenciam que a Educação Ambiental foi compreendida como um lugar estratégico para a reprodução das condições sociais do modo de produção capitalista; foi cooptada pelo interesse econômico, serviu como um ambiente institucional perfeito para a reprodução dos valores neoliberais que perpassam a pauta ambiental, posto que existem distintas formas de se pensar e fazer a sustentabilidade, permanentemente em disputa por legitimidade.

Dessa cooptação resulta a manipulação dos sentidos pedagógicos, desfigurando o que se entende por Educação Ambiental. Cooptada e manipulada, desdobrou-se numa Educação Ambiental dissimulada, que carrega a intencionalidade persuasiva e domesticadora dos indivíduos. E, assim, passou a disseminar, ampla e irrestritamente, as ideias que convém ao capital, apresentando o contorno da problemática ambiental segundo a ótica do ambientalismo de mercado e oferecendo soluções aos desafios ambientais que agradam ao mercado, pois apresentam o padrão normal,modelo do sujeito ecológico identificado como o ambientalista moderado, aquele preocupado em fazer a sua parte na sociedade, disposto individualmente a mudarseu hábito de consumoe descarte. Atua como um mecanismo de compensação do risco da supressão da regulação ambiental pública impondo subliminarmente ao cidadãoconsumidor verde a fictícia responsabilidade individual pelo esverdeamento da economia.

$\mathrm{O}$ direcionamento para essa conscientização ecológica o deixa preocupado com o destino do lixo doméstico e com o consumo sustentável, mas o mantém alienado acerca da lógica predatória do modo de produção capitalista. Deixa esse sujeito ecológico preocupado com a expansão genérica da fronteira agrícola, mas o mantém indiferente à matriz desenvolvimentista estar calcada no robustecimento do setor primário, notoriamente predatório.

Com efeito, tornou-serecorrente verificar diagnósticos de uma Educação Ambiental reprodutivista:Stahelin, Accioly e Sanchez (2015),por exemplo, analisaram como a ideologia neoliberal influenciou as práticas de Educação Ambiental no Brasil, investigando o papel desempenhado pelo Estado na mobilização de programas nacionais nãoformais para promover o desenvolvimento rural sustentável na agricultura familiar. Constataram que a Educação Ambiental vive uma profunda contradição ideológica entre uma retórica que partilha da perspectiva Crítica e uma prática que reforça o modo de produção capitalista. Para os autores, as iniciativas governamentais de Educação Ambiental absorveram os elementos-chave do neoliberalismo: um programa educacional que moldaa agricultura familiar baseada no modo de produção capitalista.

Essa Educação Ambiental reprodutivistadissemina uma ideia de meio ambiente, sociedade, sustentabilidade e de educação que é, exatamente, a mesma ideia de meio ambiente, sociedade, sustentabilidade e educação, do ambientalismo de mercado.Essa Educação Ambientalconservadora reproduz os valores e interesses da burguesia, tratando-os como valores e interesses universais; e, assim, a Educação Ambiental passou a ser controlada, tendo seus sentidos político-pedagógicos alinhados à perspectiva cultural do modo de produção capitalista.

No final, o sujeito ecológico conscientizado pela Educação Ambiental se convertenuma peça da engrenagem do modo de produção capitalista, obediente ao seu papel social designado pela burguesia. Adquirem-se valores, comportamentos e conhecimentos compatíveis com os interesses do mercado.Advoga por um olhar específico sobre como deve ser o sujeito ecológico: investido do sentimento individual de responsabilidade e altruísmo 
para com a construção da sustentabilidade, esse sujeito ecológico se curva aos ditames do capital e ageda maneira que lhe impõe, acriticamente, seguindo fielmente os preceitos de uma específica e particular sustentabilidade, a do mercado.

Esse cidadão crê estar contribuindo com a sustentabilidade, enquanto se converte em um ator funcional do mercado. Essa Educação Ambiental reprodutivista procura,incansavelmente,manter viva a ciranda do comprar-e-vender, na medida em que dialoga com a perspectiva do Consumo Verde, convida a fazer circular a mercadoria e fluir o capital, estimula a pensar nos termos da lógica do mercado, com o mantra da reciclagem sempre que se aborda a questão dos resíduos sólidos no ato pedagógico.

Não ésem propósito que se verificam inúmeras propostas de criação de projetos de lei para a Educação Ambiental, que assumem, escancaradamente, a pauta do ambientalismo de mercado, indiscutivelmente como um aparelho ideológico de Estado, a exemplo do Projeto de Lei da Câmara n ${ }^{\circ}$ 270/2009, de autoria da Deputada Rebecca Garcia (PP/Amazonas), que veio a se tornar a Lein $^{\circ} 13.186 / 2015$, que institui a Política de Educação para o Consumo Sustentável, na qual se destaca o artigo $3^{\circ}$, que

[...] incumbe ao poder público, em âmbito federal, estadual e municipal promover campanhas em prol do consumo sustentável, em espaço nobre dos meios de comunicação de massa, e capacitar os profissionais da área de educação para inclusão do consumo sustentável nos programas de educação ambiental do ensino médio e fundamental.

A exemplo, também, do Projeto de Lei $\mathrm{n}^{\circ}$ 706/2011, de autoria do Deputado EnioBacci (PDT/RS), que visava instituir a Semana da Reciclagem e Meio Ambiente em Escolas Públicase, ainda, do Projeto de Lei do Senado $n^{\circ} 221 / 2015$, de autoria do Senador Cássio Cunha Lima (PSDB/PB), que visava incluir como objetivo fundamental da educação ambiental "o estímulo a ações, individuais e coletivas, que promovam o uso sustentável dos recursos naturais, com vistas à adoção de práticas de reutilização, reciclagem, reuso de produtos e matérias-primas e ao consumo consciente". Todos empenhados no estabelecimento da norma padrão para a Educação Ambiental, sempre girando em torno da sociabilidade do mercado.

Além da difusão ideológica do novo padrão sociocultural a ser implantado, o ocultamento da realidadeé outro poderoso instrumento ideológico que assegura a invisibilidade das contradições do modelo e, consequentemente, evita a indignação e garante o apaziguamento social, por suprimir a possibilidade da crítica anticapitalista constar no repertório temático da Educação Ambiental. A Educação Ambiental reprodutivista omite as contradições do modelo societário baseado no mercado, que se pretende universal quando, na verdade, é particular e é responsável pelo aprofundamento do abismo das desigualdades de classe.

É nessa perspectiva que a Educação Ambientalreprodutivista é responsável, também, pelo apagamento de tudo que se passa no âmbito dos conflitos da luta ambiental, o que, evidentemente, também é de total interesse para as forças econômicas hegemônicas. Aí reside outro grande problema dessa perspectiva corrompida da Educação Ambiental, a omissão de uma dimensão estruturante da luta ambiental, que, sem ela, não são visíveis as contradições do capital, inviabilizando, então, a crítica. Assim, encobrir a realidade,camuflandoa luta sociopolítica e seu universo dos conflitos, injustiças, desigualdades e retrocessos socioambientais se torna condição vital de manutenção dessa lógica.

Quando Cosenza, Kassiadou e Sánchez (2014) se perguntam até que ponto o debate ecopolítico sobre a violação dos direitos humanos em função dos conflitos socioambientais está presente na Educação Ambiental, está se diagnosticando uma Educação Ambiental com uma grave insuficiência conceitual, que, convenientemente, cumpre seu papel de ocultamento das contradições do capital. 
O signo do ocultamento nesta Educação Ambiental reprodutivista está presente na escola pública, como se vê com o testemunho de Cosenza e Martins (2016), com a ausência de problematização acerca dos conflitos e injustiças socioambientais. Na mesma direção, Kaplan (2012) e Kassiadou (2015) conferiram que o Programa Escolas Sustentáveis, do Ministério da Educação, também não contempla nenhuma problematização acerca dos conflitos socioambientais, mesmo que as escolas onde o programa foi implantado situem-se em zonas de sacrifício, assim denominadas por estarem dentro do contexto territorial de conflitos socioambientais.

Mas a perspectiva doutrinadora da sustentabilidade a partir do agronegócio encontra espaço para florescer dentro da escola pública (LAMOSA; LOUREIRO, 2014; LOUREIRO; LAMOSA, 2015). Como reconhecem Loureiro e Lima (2012), o discurso empresarial de sustentabilidade parece ter conquistado hegemonia nos projetos de Educação Ambiental no contexto escolar.Santos, Gonçalves e Machado (2015) dão testemunho da existência de programas de Educação Ambiental empresarial implementados tecnicamente como medidas de mitigação ou compensação ambiental, mas politicamente aplicados como instrumento de controle junto às populações impactadas negativamente, visando neutralizá-las, contando,inclusive, com a colaboração das escolas no entorno do empreendimento.

Ainda no âmbito do ocultamento, cumpre lembrar que, em 2007, com reestruturação do Instituto Brasileiro do Meio Ambiente e dos Recursos Naturais Renováveis, a Coordenação Geral de Educação Ambiental (CGEAM/IBAMA), instância políticoadministrativa responsável pelas diretrizes da Educação Ambiental dentro do órgão, foi extinta. Era a única política pública federal de Educação Ambiental marcadamente a partir da perspectiva do oprimido, e não da classe dominante; que estabeleceuum conjunto de diretrizescapazes de blindar o campo contra a invasão da sociabilidade do mercado.

Com isso o Estado deixou de implementar, exatamente, a única perspectiva de Educação Ambiental que adotava a crítica anticapitalista e desagradava o mercado, aquela cuja práxis pedagógica estimulava os grupos sociais afetados pela injustiça e desigualdade ambiental a participar nos espaços cidadãos da gestão ambiental pública, no exercício democrático do controle social das políticas públicas desenvolvimentistas aplicados no território. Essa medida constituiu-se como um silenciamento político, como um ato repressor, e entra no saldo dos retrocessos ambientais acumulados na conta do signo antiecologista. Terá sido apenas uma infeliz coincidência a única instância que, efetivamente, impediu a cooptação ideológica dentro do Estado brasileiro ter sido extinta?

Ainda na perspectiva do ocultamento da realidade, essa Educação Ambiental reprodutivista pauta-se,também,pela recorrente lógica da difusãodos bons exemplos de experiências exitosas de uma determinada sustentabilidade, buscando a pacificação social em torno de uma agenda comum, e não a exposição das contradições do capital. Investe na lógica do anúncio das boas práticas de gestão ambiental, sugerindo que a insustentabilidade automaticamente se converteria pelo apelo convincente do bom exemplo, como se a questão se resumisse a um processo de conscientização, avançando sobre o terreno da ignorância humana. A compreensão de luta ambiental, aqui, se resume ao esforço da divulgação do anúncio da sustentabilidade à mais ampla audiência, distante da denúncia da insustentabilidade.

É o que se constata, por exemplo, do material pedagógico produzido pelo Departamento de Educação Ambiental do Ministério do Meio Ambiente, em 2012, as Boas práticas em Educação Ambiental na Agricultura Familiar: exemplos de ações educativas e práticas sustentáveis no campo brasileiro (BRASIL, 2012), onde o tema que seria próximo do estruturante - Educação Ambiental na prevenção e na resolução de conflitos socioambientais - se dilui em um dos quatorze temas das boas práticas. E, também, de outra iniciativa do Departamento de Educação Ambiental, a Estratégia Nacional de Educação 
Ambiental e Comunicação Social na Gestão dos Resíduos Sólidos, que conta com uma plataforma na internet para divulgar os exemplosinspiradores, um mecanismo de reprodução social, posto que ali se encontram registradas apenas as práticas voltadas ao universo da reciclagem e destinação correta do lixo, sem nenhum espaço para a problematização da Obsolescência Planejada.

Tudo indica que o processo de hegemonização dessa Educação Ambiental reprodutivista foi amplo o suficiente, para não se encontrar nos programas governamentais de Educação Ambiental no contexto dos resíduos sólidos e da crise hídrica, as duas atuais grandes vedetes temáticas, nenhuma reflexão que polemize o modelo, que problematize a realidade injusta e desigual, que revele a dimensão da luta social em torno do acesso e uso dos recursos naturais, que exponha as contradições do capital. A crítica anticapitalista foi extirpada dos programas governamentais de Educação Ambiental.

Mas, como foi construído o consenso absoluto e inquestionável em torno da Reciclagem como a ideia-chave determinante da Educação Ambiental, no contexto dos resíduos sólidos, para combater a práticado desperdício do metabolismo urbano-industrial, como se verifica a partir de trabalhos como de Alves (2017), em que os municípios da Grande ABC paulista abordam unidimensionalmente? Porque não se estabeleceu um consenso igualmente absoluto e inquestionável da Educação Ambiental no âmbito dos resíduos sólidos, para se combater a lógicado desperdício dos recursos naturais por meio da negação da Obsolescência Planejada e da propaganda do consumismo?

Daí seu caráter de uma Educação reformista, pois aponta para soluções que ambientalmente apenas atenuam os efeitos, enquanto silencia as causas estruturais do desperdício do metabolismo urbano-industrial capitalista, mantendo intactos os fundamentos do modo de produção. Entre os benefícios ambientais e econômicos, a reciclagem certamente assegura a criação de um robusto mercado dentro da indústria da despoluição, o da logística reversa, dependente da lógica do desperdício vigorando no estilo de vida capitalista: a reciclagem é parte constituinte indissociável do mercado e o desperdício é uma necessidade funcional do sistema que vitaliza o mercado da reciclagem.

Como foi construído o consenso pleno em torno da economia de água por meio da redução do consumo para a Educação Ambiental no contexto da crise hídrica como a lógica exclusiva para combater o desperdício de água? Porque também não se estabeleceu um consenso para se combater o desperdício de água por meio da redução da demanda, lutando por autonomia na produção e armazenamento da água? Porque o signo predominante da crise hídrica se relaciona às mudanças climáticas, um fenômeno natural relativamente externo à dimensão sociopolítica, e não se relaciona ao brutal processo de apropriação privada da água para fins mercantis por parte de grandes empresas do agro-hidro-negócio?

Como foi construído o consenso em torno da invisibilidade do racismo, conflito, injustiça e desigualdade socioambiental? Como foi construído o consenso em torno do absoluto silenciamento do modelo de desenvolvimento brasileiro, que está na base de toda a desregulação ambiental pública que se abate no Brasil e América Latina? Onde está escrito, no arcabouço político-conceitual da Educação Ambiental, que a problematização desses assuntos não pertence ao domínio desse campo?

\section{A Educação Ambiental entre a subversão e a subserviência ao capital}

Na medida que a Educação Ambiental está circunscrita à dicotomia entre conservar ou transformar a realidade, ideologicamente ela se encontra situada entre o pragmatismo hegemônico neoliberal do Mercado e a radicalidade da crítica anticapitalista (LAYRARGUES, 2012). Situa-se entre dois projetos societários distintos, com propostas civilizatórias diferentes. Esse é o $X$ da questão, é aí que está o cerne da disputa ideológica a 
que todo e qualquer educador ambiental se encontra, querendo ou não, sabendo ou não. A práxis da Educação Ambiental pode deslizar toda sua potencialidade nesse eixo entre os dois polos. As opções estão dadas, e cabem aos responsáveis pelas políticas, programas e projetos de Educação Ambiental, as escolhas a fazer: ao conceber e aplicar uma intervenção em Educação Ambiental, que projeto societário se tem em mente?

Essa é a polarização de fundo que interessa ao campo da Educação Ambiental brasileira se posicionar: não é mais possível bradar por mais Educação Ambiental no singular, quando se tornou necessário reconhecer qual projeto societário essa Educação Ambiental defende: uma Educação Ambiental reformista,subserviente ao capital, ou uma Educação Ambiental transformadora, rigorosamente anticapitalista, radicalmente alinhada com a construção de sociedades sustentáveis, pela perspectiva dos oprimidos.

A expressão sob o signo antiecologista procura designar o período histórico em que é possível observar, claramente, a dinâmica processual da estrutura dos aparelhos repressores e ideológicos de Estado em ação, diante da imposição de sacrifícios, realizando seu processo vivo do exercício do poder instituído e simbólico para assegurar a manutenção da hegemonia, neutralizando o campo político do ambientalismo diante da agudização da ofensiva neoliberale mantendo intacta a sociabilidade do capital. Mas neutralizando, também,o poder subversivo da própria Educação Ambiental, que foi passivamente transformada em um clássico modelo reprodutivista. A perspectiva demarcada pela produção teórica de Althusser, Bourdieu e Gramsci permite que se veja a engrenagem dos aparelhos repressivos e ideológicos de Estadoem movimento, pavimentando o processo de reprodução social garantidor da manutenção da ordem capitalista e dos privilégios da burguesia.

Demarcada pelo mesmo contexto estrutural do antiecologismo, a Educação Ambiental brasileira se torna reprodutivista na exata medida que se estabeleceessa nova configuração das forças em disputa no campo da luta ambiental, acenando,francamente, a favordo signo antiecologista. Signo representativo do vertiginoso aprofundamento neoliberal na economia do continente latino-americano, para destravar as restrições que impediam a exploração das commodities, pois as terras tradicionalmente ocupadas por povos indígenas e quilombolas estão, junto das Unidades de Conservação e das Áreas de Preservação Permanente, em lugares errados, que precisam ser removidos para não comprometer a rentabilidade do desenvolvimentismo extrativista-predatório.

Dessa forma, a hegemonia do capital se sustentou à custa do aparelho repressor de Estado, constituído pelo conjunto dos retrocessos ambientais demarcados pela desregulação ambiental pública e pelo conjunto de ataques aos direitos territoriais dos povos tradicionais, e se sustentou também com o aparelho ideológico de Estado, constituído pelo conjunto de narrativas enaltecedoras de um ethos ecológico identificado com o ambientalismo moderado, ou pragmático, direcionando o sujeito ecológico a assumir a norma padrão que abrange um determinado conjunto de valores, conhecimentos, habilidades e atitudes condizentes com a racionalidade econômica,convertendo-oa merapeçada engrenagem da ciranda do comprar-evender, submisso ao mercado e, passiva e alienadamente, conformado com seu papel social a desempenhar na sociedade, profundamente identificados com a ideologia dominante.

Nesse quadro de hegemonia da Educação Ambiental subserviente ao capital, a Educação Ambiental sofreu uma bifurcação no seu sentido histórico: passou a ser dirigida pelo capital e partiu para outro destino. A Educação Ambiental está alicerçada como instrumento de dominação da classe dominante, perpetuando seus valores e o modo de reprodução social que lhe convém.A contra-hegemoniado ideal das Sociedades Sustentáveis foi rendida e sufocada. Eis a natureza do signo antiecologista dentro do campo da Educação Ambiental.

$\mathrm{Na}$ medida em que o signo do antiecologismo representa o aprofundamento do exercício da hegemonia da sociabilidade do capital, radicalizando o grau do controle na 
manutenção da ordem neoliberal, arecomposição de forças demanda o fortalecimento da resistência contra-hegemônica. Daí a necessidade de se reafirmar o compromisso éticopolítico com as sociedades sustentáveis, e de firmar outro compromisso político-pedagógico no campo da Educação Ambiental, com a ampla sinalização de pertencimento a outro campo para além do capital, assumindo a radicalidade da luta anticapitalista, a partir da perspectiva do oprimido como condição de superação da cooptação reprodutivista.

Concordando com Santos, Gonçalves e Machado (2015), que a Educação Ambiental Crítica precisa autodeclarar-se anticapitalista e fundar-se na perspectiva das classes populares/trabalhadores e de que não é possível desprezar o contexto do capitalismo, a crise identitária anuncia a hora de revolucionar a Educação Ambiental e instituir um novo paradigma orientador para o campo.

Condição básica dessa agenda é o reconhecimento de que o campo da Educação Ambiental é atravessado pelo signo da luta ambiental, em disputa pela hegemonia do poder de legitimar o projeto societário que lhe dá sustentação. Apenas na perspectiva que parte do pressuposto de que a sociedade é o espaço inerente do conflito social, é possível perceber a correlação de forças no próprio campo da Educação Ambiental, e assim, ver como foi cooptada e instrumentalizada, deixando de ser subversiva e se convertendo numa extraordinária peça publicitária da sociabilidade do capital.

O exercício da reflexão sobre os conflitos socioambientais, o estilo de desenvolvimento, o modo de produção capitalista, a doutrina neoliberal, a propriedade privada, por exemplo, precisa ser uma constante no campo da Educação Ambiental. Se o debate sobre o caráter antiecológico do projeto de nação fundado no desenvolvimentismo capitalista não pertence ao campo da Educação Ambiental, onde mais a problematização da realidade socioambiental pode ser realizada?

Seguir o caminho da hegemonização da Educação Ambiental Crítica exige assumir a radicalidade do projeto revolucionário que representa a orientação central do campo da Educação Ambiental brasileira: o Tratado de Educação Ambiental para Sociedades Sustentáveis. Assumir a ideia de sociedades sustentáveis como projeto societário no sentido da transformação social, significa abandonar a ideia desenvolvimentista. E significa pensar e praticar a Educação Ambiental para além de todo pacote ideológico embutido tanto na ideia desenvolvimentista, como na ideia de sustentabilidade elaborada a partir do desenvolvimentismo ${ }^{5}$.

A ideia desenvolvimentista é uma ideia criada na e para a sociedade capitalista, e uma sociedade capitalista é uma sociedade fundada na ideia do Capital na centralidade de toda dimensão da vida humana. O Capital, por sua vez, está fundado na ideia da propriedade privada, que, no seu sentido último, significa estar baseado na ideia de privação. Cria o reino da necessidade, para suprir a privação ${ }^{6}$, mas sempre no âmbito do mercado, obrigando a todos

\footnotetext{
5 A Educação Ambiental reprodutivista procura, incessantemente, manter viva a ideia desenvolvimentista, a exemplo dos esforços empreendidos pelas Nações Unidas para consolidar a Década da Educação para o Desenvolvimento Sustentável (2005-2014). Findo esse longo período de inculcação ideológica, sucedeu-se a iniciativa, também das Nações Unidas, da Educação para os Objetivos de Desenvolvimento Sustentável (UNESCO, 2017), que conta com a parceria do Ministério do Meio Ambiente e do Ministério da Educação, para a disseminação de kits didáticos contendo uma publicação e uma série de vídeos para crianças de 7 a 11 anos de idade, que visa aumentar a conscientização da comunidade escolar sobre a importância do desenvolvimento sustentável. O que é um grave problema, posto que a prática da sustentabilidade no desenvolvimentismo opera a partir da perspectiva capitalista, e a instância político-administrativa responsável pela condução da política brasileira de Educação Ambiental dá a bênção necessária à legitimação da hegemonia do capital, chancelando esse movimento ideológico.

${ }^{6}$ Hoje, a propriedade privada priva a produção gratuita dos serviços ecossistêmicos, e é nesse sentido que se torna indispensável ressignificar a função social da propriedade privada. Privatizar a natureza e mercantilizar a
} 
a conectarem-se na gigantesca ciranda do comprar-e-vender, onde ninguém deve escapar da lógica da produção e consumo sem, inclusive, permitir a existência de outros modos de se viver para além do capital e do regime da propriedade privada, como são os povos indígenas, quilombolas, campesinos, ribeirinhos, seringueiros, caiçaras, pantaneiros, entre tantos outros povos originais, que demarcam claramente o sentido essencial das sociedades sustentáveis: aquelas que possuem autonomia.

Povos tradicionais são sustentáveis porque são,territorial e culturalmente,autônomos, simplesmente porque sabem viver, com distintos modos de propriedade coletiva, em territórios onde viceja a verdadeira infraestrutura - a natural -, que lhes garante o suprimento de todas as suas necessidades. Ali a dimensão da Vida existe em plenitude e não lhes foi privada pela dimensão das Coisas. A propriedade privada, que ali não existe, não lhes privou o acesso aos produtos e serviços ecossistêmicos que lhes assegura a reprodução de seus alternativos modos de viver.

Já nesse projeto desenvolvimentista, povos tradicionais são convidados a se 'desenvolver' de suas culturas e territórios, e não são apenas expropriados de seus laços de pertencimento biofílico, são também submetidos à força a participar do maquinário que move a ciranda do comprar-e-vender, tendo que abandonar a lógica do ser para a do ter, decretando seu ingresso definitivo no reino da privação.O capitalismo não dá espaço para quaisquer outros modos de existir fora do mercado. Estimativas apontam que são por volta de 25 milhões de brasileiros, que ocupam cerca de $1 / 4$ do território e que compartilham de regimes de propriedade distinta da privada: não são poucos os que precisam serinvisibilizadospelo sistema para ocultar suas existências e resistências, o que desmascararia o mito do progresso desenvolvimentista.

Assim, uma Educação Ambiental verdadeiramente comprometida com as sociedades sustentáveis, necessariamente se inscreve fora do desenvolvimentismoe na perspectiva do oprimido, para lembrar Freire (1970), que assinalava que a tarefa deve ser iniciada pela realidade dos grupos subalternos, do ponto de vista tanto daqueles que movimentam as máquinas do desenvolvimentismo, como daqueles que, por serem autônomos, tem constantemente seus modos e territórios de vida atacados pelo ímpeto do capital.

A Educação Ambiental que queremos necessariamente se conjuga com a Educação Ambiental que não queremos, porque essa Educação Ambiental que não queremos reprodutivista e instrumentalizada a serviço do capital -, tornou-se plenamente hegemônica ao conquistar amplo domínio nas orientações políticas sobre o fazer e o pensar o ato pedagógico da Educação Ambiental.Assim, ou a Educação Ambiental se torna Crítica ou será apenas adestramento ambiental.

Sese quer uma Educação Ambiental orientada pela transformação social, elanecessariamente carrega o signo da negação, sendo declarada e decisivamente anticapitalista. Assim, ao mesmo que tempo que se defende a Educação Ambiental Crítica, nega-se, também, essa Educação Ambiental hegemônica, subserviente ao capital: enfrentar a hegemonização da Educação Ambiental reprodutivista requer a firme recusa de continuidade dos projetos, programas e políticas conservadores na Educação Ambiental, nos governos, nas escolas, nas universidades e em quaisquer outros espaços pedagógicos de caráter público.

Vida, trazendo tudo isso para dentro do mercado, é o significado da economia verde como um novo desdobramento da acumulação do capital. 


\section{A conjugação do anúncio e da denúncia na Educação Ambiental}

Uma tarefa crucial e definidora para a perspectiva Crítica da Educação Ambiental, e em sintonia com a pedagogia da Indignação (FREIRE, 2000), que insistia não ser possível anúncio sem denúncia, é o desvelamento da realidade: se o que se espera na Educação Ambiental reprodutivista e apaziguada com o silenciamento das contradições do capital é a anulação do poder subversivo; entãoo debate político-pedagógicoda Educação Ambiental Crítica, necessariamente, passa pela revelação e exposição daquilo que é ocultado: o poder subversivo e revolucionário necessário à transformação social. $\mathrm{O}$ esforço decisivo que caracteriza a Educação Ambiental Crítica está na revelação daquilo que a Educação Ambiental reprodutivista e capitalista se empenha em ocultar, como condição para recuperar o potencial contestatório sacrificado pelo silenciamento do debate ecopolítico nas práticas conservadoras da Educação Ambiental.

Anunciar os modos de vida sustentáveis e, simultaneamente,denunciar o modo de vida insustentável é a tarefa primordial da Educação Ambiental Crítica. Defender o caminho alternativo da sustentabilidade e, ao mesmo tempo,combater o caminho hegemônico da insustentabilidade. Ser a favor de algo e de forma combinada mostrar-se em posição contrária a seu antagonista, e não simplesmente ignorá-lo como se não existisse, ou menosprezá-lo como se fosse de pequena importância. Não bastanutrir o ecologismo pragmático sem também impedir o avanço do antiecologismo. Não basta incentivar o ecocentrismo sem ao mesmo tempo combater a face capitalista do antropocentrismo.

Se não se agir, também, sobre as causas estruturais da insustentabilidade, as medidas de política ambiental não serão efetivas, porque não basta atuar na gestão ambiental no enfrentamento da crise socioambiental se não se dialetizaras evidências da degradação socioambiental com suas causas estruturais na economia de mercado. Não basta aderir à agroecologia sem, concomitantemente, se opor ao agronegócio exportador de commodities e problematizar a necessidade da reforma agrária: a lógica predatória do setor produtivo primário seguirá determinada pelo papel geopolítico que o país representa na periferia do sistema capitalista e o espaço da agroecologia será marginal, como um nicho de mercado.

A superação da insustentabilidade passa pela dialética, só se faz com a luta contra o antagônico da sustentabilidade, mas, para que isso ocorra, é necessáriorecuperar o sentido contestatório e o poder subversivo que foi subtraído da Educação Ambiental brasileira. Contudo, ainda assim, fica a dúvida levantada por Santos, Gonçalves e Machado (2015): até onde uma Educação Ambiental Crítica, que se coloca na posição de contra hegemonia encarregada da subversão da ordem social, consegue avançar na superação do capitalismo, sem sofrer cooptação, censura ou intimidação?

\section{Conclusão}

Ao longo da última década, a Educação Ambiental brasileira enquadrou-se fielmente na perspectiva que se espera da educação voltada à questão ambiental no capitalismo: reformista na forma e pragmática no conteúdo. Assim ajustada, a Educação Ambiental passou a contribuir funcionalmente com a reprodução do ethos capitalista, servindo como a referência uniforme e indistinta para a mesma sociedade de classe. Camuflada pelo legítimo processo pedagógico de conscientização ambiental, a cultura capitalista, sutil e subliminarmente, passou a ser disseminada na intencionalidade político-pedagógica da Educação Ambiental, por meio da sua recorrente associação com a mensagem ecológica.

O capitalismo expressou seu poder de controle, por meio do exercício da força simbólica de dominação, transmitindo seu estilo de pensamento para dentro do campo da Educação Ambiental. Agora, salvo nos espaços entrincheirados da perspectiva 
Crítica,prevalentes numa fração do setor acadêmico e dos movimentos sociais, a Educação Ambiental na sociedade brasileira é exatamente a mesma Educação Ambiental que se esperaria ver em uma sociedade capitalista. Abrindo mão da transformação social e sendo reformista, a Educação Ambiental se investiu da ideia do fim das ideologias e naturalizou o capitalismo, aceitando-o como a doutrina societária definitiva e inquestionável, contribuindo, assim, com sua reprodução.

Naturalizando o capitalismo e retirando a luta de classes do seu enquadramento, essa Educação Ambiental reprodutivista se forja a partir da ideia que a missão da Educação Ambiental seja a de avançar exclusivamente sobre o terreno da ignorância, e não da ganância. Assim posto, a tarefa está no fomento à disseminação do conhecimento para superar o comportamento individual ecologicamente inadequado, marginalizando a dimensão estrutural dos conflitos sociais na esfera política e econômica em torno de interesses contraditórios e relações de poder desiguais sobre os bens ambientais. Assumindo esse postulado, adota uma perspectiva difusionista e normativa, e o êxito da Educação Ambiental dependerá, unicamente, da ampliação da divulgação da mensagem ecológica a todos indistintamente, uma impossibilidade para uma sociedade de classe.

Exercendo seu poder de controle seletivo sobre a mensagem, essa Educação Ambiental reprodutivista conquista hegemonia quando dissemina consensos absolutos, doutrinadores, que giram em torno da difusão exclusiva da agenda positiva, em torno de uma pauta pacificada dos bons exemplos ou das boas práticasinspiradoras para pavimentar o caminho da sustentabilidade pelo cidadão responsável; enquanto necessariamente omite a pauta negativa, ocultando os elementos estruturais da insustentabilidade inerente à lógica do capitalismo.

Esse ocultamento tornainvisivel o racismo, o conflito, a desigualdade socioambiental, as lutas populares de resistência e, também, o próprio antiecologismo,silenciando a insustentabilidade da economia globalizada de livre-mercado neoliberal, omitindo a compreensão da lógica da degradação ambiental e da própria construção da sustentabilidade serem atravessadas pela luta de classes e determinadas pelo capitalismo. Nesse duplo papel da difusão ideológica, o estabelecimento da norma-padrão e a interdição da problematização do contraditório, o ocultamento das contradições é fundamental para assegurar a reprodução das condições sociais, mantendo a estabilidade da ordem social inabalada, pois desempenha função preponderante na conformação e acomodação dos sujeitos, apaziguando a contestação e eliminando a paisagem da arena pública como espaço de manifestação cidadã, onde a subversão ganha legitimidade.

O resultado dessa Educação Ambiental reprodutivista que conquistou hegemonia é a formação de um sujeito ecológico manipulado, alinhado ao pensamento social capitalista: sujeitado pelo adestramento ambiental para se adaptar, voluntária e altruisticamente, a novos comportamentos individuais. Absorve passivamente o repertório de valores, conhecimentos e habilidades que o condiciona a pensar e agir na direção da sustentabilidade, exclusivamente pela perspectiva do ambientalismo de mercado, reproduzindo, acriticamente, sentidos ideológicos que, em nome da conscientização ambiental, se prestam a realizar o interesse do capital.

Assim conformado, esse sujeito ecológico se vê investido, sempre, pela responsabilidade individual do bom consumidor, calcada na ação individual na esfera privada, tornando-se plenamente capaz de contribuir com mudanças superficiais e reformistas, e totalmente incapaz e privado do exercício cidadão na luta política coletiva pela transformação social, pautada pela crítica anticapitalista. Combinando, como diria Paulo Freire (2000) "eficácia técnica e ineficácia cidadã a serviço da minoria dominante". Assim domesticado, esse sujeito ecológico, civilizado mas despolitizado, se torna pacificamente instrumental ao sistema, porque só atua a favor de uma sustentabilidade muito particular, fazendo 
individualmente a sua parte estritamente dentro da regra, ignorando a crítica ecopolítica e a luta coletiva para interromper a lógica predatória intrínseca do capitalismo.

E, dessa forma, instrumentalizada para se tornar subserviente ao capital, a Educação Ambiental brasileira, que se orientava ${ }^{7}$ pelo Tratado de Educação Ambiental, aprofundou seu conservadorismo pedagógico e teve como resultado final, seu conteúdo crítico ecopolítico esvaziado, seu poder subversivopacificado, seu potencial contestatórioneutralizado, sua resistência anticapitalista sufocada, sua radicalidade do rumo societário orientado pela transformação social anulada.

Assim, constitui-se o papel funcional da Educação Ambiental reprodutivista e conservadora no capitalismo, que conquistou plena hegemonia no Brasil: reproduzir os valores e modos de vida da sociedade capitalista e manter o controle sobre a ordem social, evitando a dissidência subversiva do ecologismo popular, que poderia ameaçar a ordem capitalista.

\section{Referências}

ALVES, P.M. Análise dos enfoques da educação ambiental voltados ao tema resíduos sólidos na região do Grande ABC/SP: uma análise baseada na Política Nacional de Resíduos Sólidos.Dissertação(Mestrado em Análises Ambientais Integradas) - Universidade Federal de São Paulo, São Paulo, 2017.

ALTHUSSER, L. Ideologia e aparelhos ideológicos de estado. Lisboa: Presença. 1970.

BOURDIEU, P., PASSERON, J.C. A reprodução: elementos para uma teoria do sistema de ensino. $3^{\mathrm{a}}$ ed.Rio de Janeiro: Francisco Alves, 1992.

BRASIL. Ministério do Meio Ambiente: Boas práticas em educação ambiental na agricultura familiar: exemplos de ações educativas e práticas sustentáveis no campo brasileiro. Brasília: MMA, 2012.

BRÜGGER, P. Educação ou Adestramento Ambiental? Florianópolis: Letras Contemporâneas, 1994.

CARVALHO, I.C.M. Territorialidades em luta: uma análise dos discursos ecológicos. 142p. Dissertação (Mestrado em Educação) Fundação Getúlio Vargas, Rio de Janeiro, 1989.

COSENZA, A., KASSIADOU, A., SANCHEZ, C. Educação ambiental e direitos humanos: necessárias articulações a partir da justiça ambiental e da ecologia política. In: SILVA, A.M.M., TIRIBA, L. (Orgs.) Direito ao ambiente como direito à vida: desafios para a educação em direitos humanos. São Paulo: Cortez, 2014. p. 21-46.

COSENZA, A.; MARTINS, I. Justiça ambiental e conflito socioambiental na prática escolar docente. In: SIMPÓSIO INTERNACIONAL SOBRE ANÁLISE DE DISCURSO, 4, 2016, Belo Horizonte. Anais... Belo Horizonte: UFMG,2016.

FREIRE, P. Pedagogia do Oprimido. Rio de Janeiro: Paz e Terra, 1970.

FREIRE, P. Pedagogia da Indignação: cartas pedagógicas e outros escritos. São Paulo: Editora Unesp, 2000.

\footnotetext{
${ }^{7}$ Até que ponto o Tratado de Educação Ambiental ainda é, de fato, uma fonte de inspiração, posto seu posicionamento ideológico de pertencimento ao campo contra-hegemônico do ecologismo popular, ao lado daqueles que representam outros modos de viver além do capital, em suas lutas pelo direito à autodeterminação cultural e territorial?
} 
GUDYNAS, E. Izquierda y ecología: los bagres de Lula y las ideas verdes de la mulata. SemanarioVoces, Montevideo, 10 setiembre 2009. p. 13.

GUIMARÃES, M. Educação ambiental: no consenso, um embate? Campinas: Papirus, 2000.

KAPLAN, L. Análise preliminar do projeto Escolas Sustentáveis: estudo de caso da primeira escola sustentável do Brasil, na Baía de Sepetiba (RJ). In: XVI Encontro Nacional de Didática e Prática de Ensino, 16, 2012, Campinas. Anais...Campinas: UNICAMP, 2012. p.13-25.

KASSIADOU, A. Escolas Sustentáveis e Conflitos Socioambientais: reflexão sobre o programa governamental das Escolas Sustentáveis sob a ótica da Justiça Ambiental. 160p. Dissertação (Mestrado em Educação), Universidade Federal do Estado do Rio de Janeiro, Rio de Janeiro, 2015.

LAMOSA, R., LOUREIRO, C.F.B. Agronegócio e educação ambiental: uma análise crítica. Ensaio, v.22, n.83, p.533-554, abr./jun. 2014.

LAYRARGUES, P.P. A cortina de fumaça: o discurso empresarial verde e a ideologia da racionalidade econômica. São Paulo: Annablume, 1998.

LAYRARGUES, P.P. A resolução de problemas ambientais globais deve ser um tema-gerador ou a atividade-fim da educação ambiental? In: REIGOTA, M. (Org.) Verde cotidiano: o meio ambiente em discussão. Rio de Janeiro: DP\&A, 1999. p. 131-148.

LAYRARGUES, P.P. Ideology and the environment: business leaders adopt a strategy of environmental discourse regarding ISO 14000. Ciência e Cultura, São Paulo, v. 52, n. 3, p.148153,maio/jun.2000.

LAYRARGUES, P.P. O cinismo da reciclagem: o significado ideológico da reciclagem da lata de alumínio e suas implicações para a Educação Ambiental. In: LOUREIRO, C.F.B.; LAYRARGUES, P.P., CASTRO, R.C. de (Orgs.). Educação Ambiental: repensando o espaço da cidadania. São Paulo: Cortez, 2002. p.179-219.

LAYRARGUES, P.P. Muito além da natureza: Educação Ambiental e reprodução social. In: LOUREIRO, C.F.B.; LAYRARGUES, P.P., CASTRO, R.C. de (Orgs.).Pensamento complexo, dialética e educação ambiental. São Paulo: Cortez, 2006. p. 72-103.

LAYRARGUES, P.P. Para onde vai a Educação Ambiental? O cenário político-ideológico da Educação Ambiental brasileira e os desafios de uma agenda política crítica contra-hegemônica. Revista Contemporânea de Educação, Rio de Janeiro, v. 7, nº 14, p. 398-421.ago./dez. 2012.

LAYRARGUES, P.P. Antiecologismo no Brasil: reflexões ecopolíticas sobre o modelo do desenvolvimentismo-extrativista-predatório e a desregulação ambiental pública. In: OLIVEIRA, M.M.D., MENDES, M., HANSEL, C.M., DAMIANI, S. (Orgs.). Cidadania, Meio Ambiente e Sustentabilidade. Caxias do Sul: EDUCS, 2017. p.325-356.

LAYRARGUES, P.P. Quando os ecologistas incomodam: a desregulação ambiental pública no Brasil sob o signo do Antiecologismo. Revista Pesquisa em Políticas Públicas.No prelo.

LAYRARGUES, P.P.; LIMA, G. As macrotendências político-pedagógicas da Educação Ambiental brasileira. Ambiente e Sociedade, São Paulo, v.17, n.1, p. 23-40, jan./mar. 2014.

LIMA, G.F. da C. Educação Ambiental no Brasil: formação, identidades e desafios. Campinas: Papirus, 2011. 
LOUREIRO, C.F.B. Educação ambiental e classes populares: teoria e prática de uma pesquisa participante. Dissertação (Mestrado em Educação) - Pontifícia Universidade Católica do Rio de Janeiro, Rio de Janeiro, 1992.

LOUREIRO, C.F.B.; LAMOSA, R. A educação ambiental e o papel das escolas públicas na valorização da imagem do agronegócio. Comunicações, Piracicaba, Ano 22, n.2, p.111-135.2015.

LOUREIRO, C.F.B.; LIMA, M.J.G.S. A hegemonia do discurso empresarial de sustentabilidade nos projetos de educação ambiental no contexto escolar: novas estratégias do capital. Revista Contemporânea de Educação, Rio de Janeiro, v.7, n.14, p.289-303, ago./dez. 2012.

LOVELOCK, J.E. Gaia: um novo olhar sobre a vida na Terra. Lisboa: Edições 70, 1979.

MEADOWS, D.L. Limites do Crescimento. São Paulo: Perspectiva, 1972.

SCHMIDHEINY, S. Mudando o rumo: uma perspectiva empresarial global sobre desenvolvimento e meio ambiente. Rio de Janeiro: Editora da FGV, 1992.

SANTOS, C.F. dos; GONÇALVES, L.D.; MACHADO, C.R. da S. Educação Ambiental para Justiça Ambiental: dando mais uns passos. Revista Eletrônica do Mestrado em Educação Ambiental, Rio Grande, v.32, n.1, p.189-208, jan./jul. 2015.

SIQUEIRA, T.V., KAPLAN, L. A educação ambiental como estratégia de sociabilidade. Revista Vitas, Niteroi, v. 4, n.8, 25 p, set. 2014.

STAHELIN, N., ACCIOLY, I., SANCHEZ, C. The promise and peril of the state in neoliberal times: implications for the critical environmental education movement in Brazil. Environmental EducationResearch, v. n., p.433-446, jan. 2015.

UNESCO. Educação para os Objetivos do Desenvolvimento Sustentável: objetivos de aprendizagem. Paris: UNESCO, 2017. 